\title{
Understanding Drivers and Challenges of Multi-actor Collaborations at the Local Level
}

\author{
Qianli Yuan \\ University at Albany, SUNY \\ qyuan@albany.edu \\ J. Ramon Gil-Garcia \\ University at Albany, SUNY \\ Universidad de las Americas Puebla \\ jgil-garcia@albany.edu
}

\author{
Karyn Doke \\ University at Albany, SUNY \\ kdoke@albany.edu \\ Mariya Zheleva \\ University at Albany, SUNY \\ mzheleva@albany.edu
}

\author{
Mila Gasco-Hernandez \\ University at Albany, SUNY \\ mgasco@albany.edu \\ Petko Bogdanov \\ University at Albany, SUNY \\ pbogdanov@albany.edu
}

\begin{abstract}
In a world increasingly characterized by complexity and ambiguity, problem solving is often achieved through collaboration among multiple actors in multi-level settings, involving national, state, and local agencies. Yet, our knowledge is limited in terms of the drivers and challenges of collaborations that require both inter-organizational collaboration and collaboration with citizens. Using a case study of the development of a mobile app for emergency preparedness and response, this study explores key drivers and challenges of multi-actor collaboration at the local level. Our results show that local leadership and direct communication are key drivers for both interorganizational collaboration and collaboration with citizens and that political dynamics are a challenge regarding inter-organizational collaboration. The two types of collaboration become distinct and independent processes while they complement each other to achieve the purposes and goals shared among different actors.
\end{abstract}

\section{Introduction}

In response to increasing complexity and uncertainty of public problems across jurisdictional lines, the notion of collaboration has become one major term in both literature and practice $[1,2]$. Collaboration could be defined as "the linking or sharing of information, resources, activities, and capabilities by organizations in two or more sectors to achieve jointly an outcome that could not be achieved by organizations in one sector separately" [3]. Public managers find themselves not solely as unitary leaders of unitary organizations but operating in multiorganizational arrangements to solve problems that cannot be solved, or solved easily, by single organizations [4]. They identify horizontal networks of public, private, and nonprofit organizations as the new structures of governance, calling for collaboration in response to public problems across boundaries [5]. In addition, citizens become an increasingly important actor in the public governance and they seek additional avenues for engagement, which can result in new forms of collaborative problem solving [4].

Public organizations create and sustain collaboration often in hoping to gain "collaborative advantage" $[6,7]$. The interaction among multiple actors may not only enhance organizational performance by using each sector's strengths while compensating for each sector's weaknesses, but also enhance trust and legitimacy, social capital, and an informed and active citizenship through constant interactions $[8,9]$.

At the same time, collaboration is neither easy nor always effective due to its complexity [7, 10]. The complexity occurs when collaboration is manifesting itself on multiple levels and with multiple actors [11]. Different types of collaboration could happen between government organizations [5], between public organizations and private organizations [2, 12], between public organizations and non-profits [13], and between public organizations and citizens $[14,15]$. In this regard, specific projects may often involve collaboration at both the organizational level (inter-organizational collaboration) and the individual level (collaboration with citizens) [7, 16]. While inter-organizational collaboration brings together the diverse knowledge, resources, and expertise of different organizations, engaging individual citizens allows multiple voices to be heard to understand public needs and better inform public decisions to address those needs $[17,18]$.

Despite the multi-level and multi-actor nature of collaboration, studies often exclusively focus on one type of collaboration or one unit of analysis (individual or organizational) and have hardly approached 
collaboration from a multi-dimensional perspective. [11, 18, 19]. While these studies identify drivers, challenges or benefits of each type of collaboration, there is still limited knowledge on the (additional) drivers and challenges of multi-actor collaboration, that is the joint action of inter-organizational collaboration and collaboration with citizens.

Our study aims to contribute to address this gap by answering the following research question: what are the drivers and challenges of inter-organizational collaboration and collaboration with citizens when both processes happen simultaneously? To do so, we conduct a case study through in-depth interviews in the town of Thurman, Upstate New York

\section{Literature Review}

Both literature about inter-organizational collaboration and collaboration with citizens has explored the drivers and challenges of each type of collaboration. Although research has acknowledged potential relations, knowledge is limited about the simultaneously interactions between these two forms of collaboration $[18,19]$. This section reviews two streams of literature and identifies the knowledge gap that leads to the research question.

\subsection{Drivers and challenges of inter- organizational collaboration}

There are several theoretical frameworks that address drivers of inter-organizational collaboration [1, 20]. Most of them refer to contextual determinants, such as a prehistory of cooperation and interdependence, which may result in high levels of trust, commitment and honest communications that encourage collaboration [20]. In addition, political mandates that specify collaboration membership and establish performance measures or accountability mechanisms drive governments to form collaboration. Finally, public managers' recognition of the need to address public issues together with actors in other sectors is one of the key reasons to establish collaboration [21].

Specific initial conditions also drive collaborations [3]. Among them, leadership has the ability to frame the issue in a way that diverse partners can understand its importance and its relevance to them [22]. A more salient issue provides more incentive to engage in the collaboration. Formal or informal agreements on shared aims and goals seem also critical [23]. Formal agreements enable accountability of each actor and build administrative capacity [24], while informal agreements place more flexibility in collaboration to attract relevant organizations who share similar interests, which is an important incentive to engage in inter-organizational collaboration [3].

Effective inter-organizational collaboration is often influenced by both the processes and the structure of the collaboration [3]. Regarding the process, the literature suggests that trust and commitment among stakeholders are the essence of collaboration [23]. They build confidence in organizational competence and a sense of goodwill to sustain relationships among multiple actors [25]. Often, collaborations begin with varying degrees of trust [10]. Constant communication becomes critical to build trust and commitment, as it helps to foster a shared understanding of goals of the collaboration, to establish the legitimacy of collaboration to both outsiders and collaboration members, and to explore mutual gains that drive effective collaboration [26].

Regarding the structure, previous studies agree that the characteristics of the network structure embedded in the collaboration influence the governance of collaboration [27, 28]. Collaboration develops "particularistic structures" that are composed of norms and rules of engagement to manage their joint work [5]. Further, given the complexity and flexibility of the collaboration, a collaborative structure is often dynamic and changing over time [29].

Processes and structures are often considered difficult to separate [3]. In the intersection of process and structure, leadership and governance mechanisms are important to create effective inter-organizational collaboration [3]. A champion may act as a "capacity builder" to manage the tensions surrounding unity and diversity in collaborations [5]. Governance mechanisms, which draw attention to mechanisms of decision making, power sharing, trust building, resource allocation, and congruence in partners' goals [29], aim to implement a suitable structure and process to enhance the effectiveness of goal-directed collaborations. These mechanisms enable all partners to submit inputs, to build shared commitments, and to allow individuals within each of the organizations to participate [23].

However, there are challenges to disrupt the dynamics in the inter-organizational collaboration. One of the most mentioned challenges is power and resources imbalance among actors [3]. It may hinder participants with less power to collaborate in a meaningful way. In turn, participants with less power reduce commitment to the collaboration because they fear they will be exploited [30]. Power conflicts are more likely at the early stage of establishing collaborations than at later stages $[31,32]$. In addition, the competing institutional logics hinder collaboration from building internal and external legitimacy that is essential to make it sustainable [33]. Because of collaboration's permeable boundaries, exogenous and endogenous shocks pose challenges to relations among 
actors [1]. Some members may drop out and new ones join so that the dynamics of collaboration may experience radical changes [3].

\subsection{Drivers and challenges of collaboration with citizens}

Different streams of literature have explored the drivers of collaboration with citizens. One the one hand, literature about co-production and co-creation has identified a variety of influential factors from either the organizational side or the citizen side $[34,35]$. On the other hand, literature about participatory design or usercentered design also divide those determinants into external and internal ones [36].

On the organizational side, the literature has referred to critical drivers related to the attitude of public officials, administrative culture, clarity of goals, and compatible structures and procedures [35]. Magno and Cassia [37] find collaboration with citizens is positively influenced by public employees' level of citizen orientation and expected benefits from collaboration with citizens. A marketing orientation, focusing on designing products according to the needs of customers, drives organizations to collaborate with users in the design process for product innovation [36, 38]. A riskaverse organizational culture may hinder collaboration as public employees have the perceptions of citizens as a non-reliable partner with limited ability [39]. A clearly defined goal of collaboration related to multiple citizens' needs would further motivate citizens to engage and develop a share vision with them [40]. An organizational process that includes active enrollment and recruitment as well as preparation of participant with resources helps to maximize the likelihood of positive outcomes [41]. Mechanisms for bidirectional communication has to be employed where organizations show sensitivity to the wide range of concerns owned by users to engage them in the collaboration [42].

On the citizen's side, both citizens' motivation and skills are found important drivers to engage in the collaboration [43]. Voorberg et al. [35] point out that citizens' motivation is influenced by their characteristics, sense of ownership, self-efficacy, the perceived ability, and the ease of involvement. Users are often driven by intrinsic motivation, such as enjoyment to solve problems, to engage in collaborative design projects [44]. Citizens participate in the collaboration when they have unmet demand for public services [45]. Their awareness of a shortfall in public performance drives them to engage to improve public service delivery [46]. In addition, government initiatives to provide citizens with resources relevant to the collaboration, such as specific skills or knowledge, seem to increase citizen engagement [47].
Recent studies emphasize that exercise of leadership from public organization and governance mechanisms is important [48]. Given that collaboration includes complex interactive relationships between the service providers and the citizens, leadership is needed to managing and directing the process to be sustainable and effective [39, 42]. Crosby et al. [49] argue such leadership traits are distributive, integrative, and catalyzing. Along with leadership, public organizations need to establish governance mechanisms to sustain the interaction with citizens. Building a common understanding of the design project is found to effectively facilitate users' engagement in the identification of problems, potential solutions and implementation of concrete initiatives [50, 51].

However, on the organizational side, professionals may not have sufficient community engagement skills to manage collaboration with citizens [52]. There is a need to train public employees to prepare their new roles in managing co-production of public services [53]. On the citizen side, many citizens do not have sufficient motivation to perform services in collaboration with professionals [54, 55]. There also appears to be a gap between the expected citizens' ability and their current skills to engage in and make contributions to the collaboration. The involved citizens or end-users may not be representative enough to fully capture the citizens' or users' concerns and collaboration may fail to produce satisfactory outcomes [56].

\subsection{Multi-actor collaboration in the public sector}

While inter-organizational collaboration and collaboration with citizens often happen simultaneously $[18,19]$, so far, there are limited studies that specifically examine both types of collaboration together. Those studies that do, mainly describe conceptual relations between them.

Previous literature suggests that collaboration with citizens has the potential to become an antecedent of inter-organizational collaboration [10]. Interorganizational collaboration develops as a direct result of the challenges of engaging in collaboration with citizens [18]. Citizen-led organizations empower service users to engage in the co-production process. At the same time, inter-organizational collaboration could act as an enabler of collaboration with citizens [18]. Some evidence shows that non-profit organizations enable and empower citizens they represent, and amplify their voice by ensuring that their concerns are expressed through the formal collaboration with government organizations [57]. Yet, Mazzei et al. [58] reveal a greater variety of relationships between third sector organizations and service users and suggest that 
only when service users have decision making powers as lead partners, inter-organizational collaboration is able to empower their direct involvement in the coproduction process.

Only few studies have explored drivers and challenges in the multi-actor collaboration. For example, one case study of services for autistic children highlights that collaboration with parent is prompted by inter-organizational arrangements and allocation of funds, and that trust-building among the actors played a pivotal role in nurturing a multi-actor collaboration approach [59]. Poocharoen and Ting [19] suggest that network process, network structure, and characteristics of actors are crucial to a network's performance and effectiveness of multi-actor collaboration. These studies identify leadership and network management as important determinants of successful multi-actor collaboration given their ability to build trust, to nurture constant communication, and to mobilize collective resources and knowledge. Yet, further research is needed that addresses the drivers and challenges of multi-actor collaboration. Our study aims to bridge this gap by answering the following research question: what are the drivers and challenges of inter-organizational collaboration and collaboration with citizens when both processes happen simultaneously?

\section{Research design}

\subsection{Case study}

We use a case study approach of collaboration in the development of a mobile application (the EApp) for emergency preparedness and response in the Town of Thurman, New York State [60]. We selected the case study approach for this research because it is particularly useful to respond to questions related to why or how. As multi-actor collaboration often entails complex practices, case studies are suitable to show how particular practices are developed in specific organizations and, therefore, help refine theory [61]. Qualitative case studies also allow us to study the research questions in depth while leaving room for unexpected, interesting findings that can form the basis for new hypotheses to be tested in future research [62, 63]. This is particularly useful when there is little existing research on the topic, as is the case here.

The multi-actor collaboration among local government organizations, the University at Albany, and residents in the Town of Thurman was established in 2017. The inter-organizational collaboration involves the Town of Thurman, the Thurman Fire Company, the Warren County Office of Emergency Management, and the University at Albany. This inter-organizational collaboration aims to address the needs and challenges in sharing emergency preparedness and response information in rural areas through robust models for wireless connectivity (peer-to-peer networks, a data mule unit and TV Whitespace) as well as to improve the communication of emergency information in the rural area through a comprehensive framework and a multilayer platform for timely information collection, integration, exchange and dissemination. By enhancing emergency information exchange, the collaboration intends to benefit emergency preparedness and response in the Town of Thurman.

The collaboration with citizens involves the University at Albany's researchers, firefighters, and the residents of Thurman. The purpose of the collaboration with citizens is to understand the community's needs of emergency information and to develop the prototype of the EApp that supports the collection of information from different sources. Four initial focus groups were conducted with firefighters and local residents between March and October in 2019 for the EApp co-design. In 2021, a small deployment of the prototype of the EApp was conducted for testing.

\subsection{Data collection and analysis}

To understand the collaboration dynamics, 11 interviews were conducted in 2020 that provide in-depth understanding of the drivers and challenges as well as the results achieved and potential outcomes in the future. Among them, four interviews were conducted with the residents of Thurman who participated in the co-design process, three public employees of the Town of Thurman and Warren County, and four project team members from the University at Albany. The interviews asked for the experience of different actors in the collaboration process as well as about their motivations, challenges, and benefits they felt were achieved during the collaboration. Interviews lasted approximately one hour and were recorded (upon permission of each subject) and transcribed.

All interviews were recorded, transcribed, and hand-coded line-by-line by a single person to ensure consistency [64]. Given the literature about drivers and challenges of inter-organizational collaboration and collaboration with citizens, we mainly used a deductive strategy to code the interview data [65]. This entailed using the existing literature to build the code list and to code data that matched existing concepts of drivers and challenges. The collected data was broken down into separate sections according to different points of view and was labelled considering both its content and the pre-defined code list. Based on the results of the coding process, the authors further identified the most mentioned codes and considered them as most important drivers and challenges. 


\section{Findings}

Our findings show important drivers of interorganizational collaboration and collaboration with citizens respectively. In addition, the findings identify key drivers when the two types of collaboration interact.

\subsection{Drivers and challenges of inter- organizational collaboration}

One of the key drivers to initiate interorganizational collaboration between the Town of Thurman, the Thurman Fire Company, the Warren County Office of Emergency Management, and the University at Albany, was the pressing need to communicate emergency information to local residents who live in rural areas with intermittent or non-existent mobile broadband access. As the town has experienced emergencies caused by severe weather (e.g., snowstorm or flood) but with limited access to the Internet, both first responders and local residents often found it challenging to share up-to-date emergency information. According to the interviewees, this is an important issue in the town since both first responders and residents need accurate and real-time information to better understand emergency situations and take appropriate actions. One public employee said, "I think one of the things that you'll see is that how do we get information to those that are very rural in this town? They don't have access to the white space. They don't have access to cell coverage. How do we get pertinent information to them? And the system that they [university team] described as far as being able to pass information from one member to another one would be very useful, and I saw the possibility of down the road being used in other very rural areas."

Our results also show that local leadership played an important role in establishing the inter-organizational collaboration. The county emergency service coordinator acted as a key liaison to build connections among the town government, the fire company, and the university team. According to the coordinator, he managed to "pass the message along to understand the goals and get others to be on board with the project". On the one hand, he helped the university to clarify the purpose and process of the collaboration with the language that local partners could understand. Finally, he communicated the needs of the town and fire company back to the university team to help develop a shared understanding of the problem and the goals of the collaboration.

The strong buy-in of the town leaders was also critical. Town leaders showed great interests in the project. As one interviewee put it: "she was always talking about the project and trying to bring it up in the board meetings to get others' buy-in". Such a motivated local leader helped to get more support in the town to engage in the inter-organizational collaboration.

A shared understanding among multiple parties was also important. The accurate understanding about the potential of this collaborative project and how it could be relevant to the town helped to alleviate uncertainty and gain interests from local government. "If the town does not have a clear understanding of what we are trying to do, they may be scared of a new technology and not be fully sure about how useful things we were trying to do", said one member in the university team.

To build such a shared understanding, constant communication played an important role. At the beginning of the project, communication with the local leadership ensured that the goals were clearly conveyed in a way that residents could relate to. One university team member said, "We've made clear what the goals of the project are. We've tried to make the goals of the projects easy to relate to. And I feel through our interactions we were able to maintain this understanding and to keep both community components, the leadership and the residents, up to date on what's the status of these tangible things." As the collaboration proceeded, the university team further discussed with partners the project progress and tangible outcomes so that they could have a clear expectation of potential results, which helped to gain their mutual understanding and commitment to the collaboration. "One thing we have done is trying to be very transparent. [...]. This transparency about what we were doing, communicating with [the] town supervisor and letting her know us and getting her understanding [about the project]. Through making yourself more available and through trying to really understand what's unclear and make it clear is how, as a team, we've been able to work on advancing towards this trust from the community", said one university team member.

However, one of the biggest challenges was to maintain the shared understanding with the town government. After the town leadership changed at the end of 2019, the new town leaders were not fully convinced that the EApp was the best way to keep residents informed of incipient emergencies. "There were some people that were very local, especially when they didn't understand what it is we were trying to do, especially those that were fighting the project," said one public employee. Having different political mindsets, new town leaders did not share the same perceptions of the usefulness of the EApp or had the same level of commitment as the former town leaders. Another public employee mentioned, "Our town is very politically divided. And when you started the project that was under the old supervisor, and now you're under a new supervisor. Her group may think it [white space] is a 
dying thing now also with the cable coming in. So that could be part of the reason". This misunderstanding of the purpose of the project and the role of the university team lowered the town government's commitment toward the collaboration.

\subsection{Drivers and challenges of collaboration with residents}

Our results show important drivers from both residents and researchers to establish the collaboration.

On the local residents' side, our findings show that residents were mainly motivated to engage in the collaboration by their general interests in rural area communications, and in getting information for emergency preparedness and response. On the one hand, residents of the Town of Thurman do not have stable Internet connections and they want to find an extra way of communication in the community. "I really like the idea of finding a way to communicate. When we were isolated in that way, and my nearest neighbor is one mile away, it just seems really useful to have a way to get information. And I just found that extremely useful," said one resident. On the other hand, residents recognized that it was critical to have up-to-date emergency information so that they could prepare for disruptive incidents, and acknowledged it was challenging to acquire such information without stable Internet connection. "Because there's really nothing up this way that gives you information on what's going on in this area unless something major happens. And then you need to get in the newspaper the next day, or you run across it when you're driving down the road," said one resident. The idea of an app integrating emergency information from different sources and communicating it without Internet could potentially benefit their own life and thus drove their engagement.

For researchers, our results show that continuous open and direct communication with residents and firefighters was critical to sustain collaboration with them. At the beginning, the introductory meetings, hosted by the university team, were a way to establish direct contact with residents and helped them to have a clearer understanding of how new technologies work. They also raised their interest to participate in the collaboration. One university team member said, "I think a key component is that, instead of going through the contact of the town and letting them explain, we explain directly to them in a couple of meetings. It was a bit clearer about what we were trying to do. We had slides and PowerPoint and visuals and got a bunch of questions and got feedback." Further, the iterative communication with residents regarding the app development process, each step they would be involved in, and expected outputs, helped to pass right information about the EApp and build residents' shared understanding to sustain the collaboration. "Emails, phone calls, getting people involved and then doing face to face meetings with them in order to understand what's going on. Face-to-face was absolutely important for them to see us, to hear us, to tell us their concerns, and just get to know who we were, giving a lot of information on what the project was and doing that consistently," said one university team member. Such direct communication helped to make clear residents' roles in the collaboration and keep them engaged with right expectations. "The presentation when they first started this project was really informative. So, it gave you an idea what they were looking for, what this project would do", said one resident.

Our results further show that the use of focus group, as a co-design method, was critical for the university researchers to produce positive interactions and results in the collaboration with citizens. Using plain language as much as possible to present the design of the EApp and remaining open and responsive to residents' inputs and questions encouraged residents to share their ideas freely and to stimulate useful inputs from different perspectives. As a part of their methodology, the university team used an emulator to visualize basic functions of the EApp. "We looked at the app they demonstrated it for. So that was all informative. So, they did a really good job on that. I mean they took back a lot of information. We tried to figure out the button, the color, and the fonts," said one resident. Such demonstration provided a straightforward image of the app, enabled them to play with the app, and helped to stimulate more new thoughts and inputs on the technology. Being open to provide feedback helped residents gain more understanding about the EApp and felt more interested in this collaboration. "They were open. They were listening. They gave people in a room enough time to flesh out their thoughts. I thought the questions that they asked were useful and effective. I thought that the interface was easy and that there wasn't discomfort between the people and the focus group and the people leading a focus group," said one resident.

However, the researchers still faced the challenge of involving a wider range of the population in the town. First, young population and people at work were hard to reach mainly as a result of lack of availability. Most of the current participants were retired people with more availability of time. Second, there were limited ways to disseminate the information about the project. One resident mentioned, "We don't have a newspaper. We don't have a radio station. We don't have that kind of broadband loosely communication. What is often required here is a personal conversation. It is available and it does take typically a personal approach." Third, residents mentioned that some residents had limited 
interest in technology, and therefore in collaborating in the development of the EApp.

\subsection{Interaction between the two types of collaboration}

Our results show that the inter-organizational collaboration has driven the collaboration with residents and firefighters in the Town of Thurman. Local leaders played a key role in the process.

First, our findings show that both the county emergency service coordinator and the town leadership played an important role to broadcast and spread the project information to attract more people to participate in the design of the EApp. The county emergency service coordinator helped the university team to connect with the town fire company. He helped to clarify the purpose of the project with plain language to firefighters and facilitated their engagement in the focus groups for the EApp design. In addition, the town leaders (before re-election in 2019) helped the university team to host the introductory meetings to broadcast the project information and to attract residents to participate. They also communicated with local residents about the project through word-of-mouth, illustrated the relevance of the project to residents' daily life, and encouraged them to attend the focus groups.

Second, our results show that pre-existing trust between the local leaders and the community facilitated the collaboration with residents and firefighters. One respondent said, "they were able to translate that to local residents who trust them as their local leaders and allow us to go in and get their time and their insight and their ideas." It helped to address residents' concerns about the university team's willingness and ability to care about their needs, which could have hindered their participation in the collaboration.

After the local election in 2019, the university team was able to continue collaborating with residents and firefighters, despite the new challenge brought about by the new town leadership. Local residents and firefighters were still committed to engage in the next steps of testing and deploying the EApp and were willing to support by providing their inputs and perspectives. Residents were willing to further spread the project information across the town to help recruit more participants. One resident mentioned, "I actually liked it all. It was really nice to work with everyone from the university as well as the residents in kind of bouncing ideas off each other. Because sometimes someone would think of something, and you could tell that people from the university hadn't thought of it yet. I am willing to reach out to more people who may want to participate in our groups. We can put together flyers to different places, and hopefully reach more people."

\section{Discussion}

This study aims to understand the drivers and challenges of multi-actor collaboration. Regarding the key drivers, our results first lend support to previous studies' arguments that inter-organizational collaboration is driven by the pressing need to address public issues that government cannot remedy on their own [1, 21], initial leadership [22, 66], and mutual understanding and constant communication [20,26] are critical to maintain such collaboration. Second, our findings also confirm that collaboration with citizens that citizens are driven by the unmet demand for public services [45], which in this case is the limited access to emergency preparedness and response information. Continuous open communication and highly interactive co-design activities allow participants to reveal a wide range of concerns and issues and maximize the likelihood of positive outcomes [41, 67].

Our findings further contribute to the literature by specifying key drivers that are especially important in the context of multi-actor collaboration. Among those drivers, local leadership is particularly important to establish multi-actor collaboration. Our findings suggest that it is precisely because the involvement of diverse types of actors in the collaboration that challenges increase to communicate correct ideas and to develop a shared set of goals for the collaboration that are relevant to all actors to drive their participation. Therefore, local leaders need to have the ability to interpret the collaboration in a way that diverse partners can understand its importance and its relevance to them.

Our findings indicate that the importance of local leadership also lies in building trust among different actors. Multi-actor collaboration includes actors with varying degrees of trust, which may result in more challenges in the trust-building process [10]. Local leaders become a key liaison in the center of the collaborative network to bridge different actors, as they have already established trust relations with them. Their role to build trust is especially important for partners from outside the community, the university teams in the case study, to connect with actors inside, residents, to establish and build multi-actor collaboration.

With regards to challenges, our results first confirm previous studies' findings on maintaining commitment and mutual understanding in the collaboration $[1,3]$. Further, lack of residents' motivation and/or availability in part of the community makes the collaboration with citizens [54, 55]. This leads to the lack of representativeness in participants that may not fully capture the citizens' or users' concerns and may fail to produce satisfactory outcomes [56].

Our findings indicate that local context matters to multi-actor collaboration. In this specific case, local 
political dynamics are an especially important challenge. Our case suggests that different political mindsets pose great challenges for the multicollaboration to gain the support of the whole town. Because of the difference, actions that are seen as legitimate in one side of the town may be regarded as less legitimate or even illegitimate when the other side takes in charge [68]. While actors in this case are able to develop internal legitimacy through constant communication and transparent process, the outsiders' lack of perceived legitimacy becomes a major challenge to sustain the multi-actor collaboration. This further indicates that it is critical for both outsiders and collaboration members see the collaboration as a legitimate entity in its form and interactions [26].

Interestingly, our findings also imply that multiactor collaboration may be especially vulnerable to endogenous shocks because of their permeable boundaries [1]. In our case, the change in the town leadership led to the disruption in the shared understanding of the usefulness of the EApp between the university and the town leaders. In the multi-actor collaboration, the roles of diverse actors, including leadership roles, are highly dynamic and complex to successfully maintain the collaboration [49]. Change in the actors or roles they play may result in changes in the level of trust, commitment, and mutual understanding among those actors and thus influence the sustainability of multi-actor collaboration. Challenges to manage those changes may increase in the context of multi-actor collaboration as more actors and relations are involved.

Despite these challenges at the inter-organizational collaboration, multi-actor collaborations have positive effects on building strong connections and trust with citizens. Interestingly, our findings indicate that collaboration with residents does not seem to be influenced by the challenges in the inter-organizational collaboration, as long as these residents retain the trust in the collaboration. While inter-organizational collaboration was one of the important drivers to initiate connections between the university team and residents, the sustainability of the collaboration with citizens lies more in their direct interaction and residents' strong commitment. This finding indicates that two types of collaboration could become distinct and independent processes while they complement each other to achieve the purposes and goals shared among different actors. Therefore, inter-organizational collaboration and collaboration with citizens may co-exist at different levels in the multi-actor collaboration. The strong connections formed between the university and the community may also sustain the multi-actor collaboration through unforeseen challenges such as a change in local governance in our case. Working together with both local government organizations and residents may enable to not only complement general resources at the organizational level with insights from residents, but also reveal citizens' concerns from different perspectives since the beginning. Future research could further explore the relations between the two types of collaboration and their outcomes and benefits, such as public value creation.

\section{Conclusion}

This study examined the drivers and challenges of multi-actor collaboration when inter-organizational collaboration interacts with collaboration with citizens. By conducting a case study, our results show that local leadership plays a key role in establishing and maintaining multi-actor collaboration, while political dynamics seem one of the key challenges. The two types of collaboration become distinct and independent processes while they complement each other to achieve the purposes and goals shared among different actors.

While this study provides in-depth understanding about multi-collaboration through interviews, one of the limitations of this study is generalizability of the results given the nature of single case study and the small number of interviews. Future research could use other research designs, including a comparative case study or a quantitative study to further understand drivers and challenges of multi-actor collaboration. Further, future research could also explore the benefits of multi-actor collaboration, such as creation of public value, and analyze what joint collaboration processes add to the individual processes of inter-organizational collaboration and collaboration with citizens.

\section{References}

[1] Emerson, K., T. Nabatchi, and S. Balogh, "An Integrative Framework for Collaborative Governance", Journal of Public Administration Research and Theory 22(1), 2012, pp. 1-29.

[2] McGuire, M., "Collaborative Public Management: Assessing What We Know and How We Know It", Public Administration Review 66(s1), 2006, pp. 33-43.

[3] Bryson, J.M., B.C. Crosby, and M.M. Stone, "Designing and Implementing Cross-Sector Collaborations: Needed and Challenging", Public Administration Review 75(5), 2015, pp. 647-663.

[4] O'Leary, R., and N. Vij, "Collaborative Public Management: Where Have We Been and Where Are We Going?", The American Review of Public Administration 42(5), 2012, pp. 507-522.

[5] Agranoff, R., "Inside Collaborative Networks: Ten Lessons for Public Managers", Public Administration Review 66(s1), 2006, pp. 56-65.

[6] Huxham, C., Creating Collaborative Advantage, SAGE, 1996. 
[7] Huxham, C., "Theorizing collaboration practice", Public Management Review 5(3), 2003, pp. 401-423.

[8] Benington, J., "Creating the Public In Order To Create Public Value?", International Journal of Public Administration 32(3-4), 2009, pp. 232-249.

[9] Page, S.B., M.M. Stone, J.M. Bryson, and B.C. Crosby, "Public Value Creation by Cross-Sector Collaborations: A Framework and Challenges of Assessment", Public Administration 93(3), 2015, pp. 715-732.

[10] Vangen, S., and C. Huxham, "The Tangled Web: Unraveling the Principle of Common Goals in Collaborations", Journal of Public Administration Research and Theory 22(4), 2012, pp. 731-760.

[11] Gazley, B., "The Current State of Interorganizational Collaboration: Lessons for Human Service Research and Management", Human Service Organizations: Management, Leadership \& Governance 41(1), 2017, pp. $1-5$.

[12] Klievink, B., N. Bharosa, and Y.-H. Tan, "The collaborative realization of public values and business goals: Governance and infrastructure of public-private information platforms", Government Information Quarterly 33(1), 2016, pp. 67-79.

[13] Cornforth, C., J.P. Hayes, and S. Vangen, "NonprofitPublic Collaborations: Understanding Governance Dynamics", Nonprofit and Voluntary Sector Quarterly 44(4), 2015, pp. 775-795.

[14] Cooper, T.L., T.A. Bryer, and J.W. Meek, "CitizenCentered Collaborative Public Management", Public Administration Review 66(s1), 2006, pp. 76-88.

[15] Feldman, M.S., and A.M. Khademian, "The Role of the Public Manager in Inclusion: Creating Communities of Participation”, Governance 20(2), 2007, pp. 305-324.

[16] Desportes, I., J. Waddell, and M. Hordijk, "Improving flood risk governance through multi-stakeholder collaboration: a case study of Sweet Home informal settlement, Cape Town", South African Geographical Journal 98(1), 2016, pp. 61-83.

[17] Nabatchi, T., A. Sancino, and M. Sicilia, "Varieties of Participation in Public Services: The Who, When, and What of Coproduction", Public Administration Review 77(5), 2017, pp. 766-776.

[18] Sancino, A., and C. Jacklin-Jarvis, "Co-production and Inter-organisational Collaboration in the Provision of Public Services: A Critical Discussion”, In M. Fugini, E. Bracci and M. Sicilia, eds., Co-production in the Public Sector. Springer International Publishing, Cham, 2016, 13-26.

[19] Poocharoen, O., and B. Ting, "Collaboration, CoProduction, Networks: Convergence of theories", Public Management Review 17(4), 2015, pp. 587-614.

[20] Ansell, C., and A. Gash, "Collaborative Governance in Theory and Practice", Journal of Public Administration Research and Theory 18(4), 2008, pp. 543-571.

[21] Kettl, D.F., "The Job of Government: Interweaving Public Functions and Private Hands", Public Administration Review 75(2), 2015, pp. 219-229.

[22] Page, S., "Integrative leadership for collaborative governance: Civic engagement in Seattle", The Leadership Quarterly 21(2), 2010, pp. 246-263.
[23] Seaton, C.L., N. Holm, J.L. Bottorff, et al., "Factors That Impact the Success of Interorganizational Health Promotion Collaborations: A Scoping Review", American Journal of Health Promotion 32(4), 2018, pp. 1095-1109.

[24] Sancino, A., J. Rees, and I. Schindele, "Cross-Sector Collaboration for Public Value Co-Creation: A Critical Analysis", In M. Stout, ed., Critical Perspectives on International Public Sector Management. Emerald Publishing Limited, 2018, 59-73.

[25] Sedgwick, D., "Building Collaboration: Examining the Relationship between Collaborative Processes and Activities", Journal of Public Administration Research and Theory 27(2), 2017, pp. 236-252.

[26] Ramadass, S.D., M. Sambasivan, and J.A. Xavier, "Collaboration outcomes in a public sector: impact of governance, leadership, interdependence and relational capital", Journal of Management \& Governance, 2018, pp. 1-23.

[27] Iborra, S.S., A. Saz-Carranza, X. Fernández-i-Marín, and A. Albareda, "The Governance of Goal-Directed Networks and Network Tasks: An Empirical Analysis of European Regulatory Networks", Journal of Public Administration Research and Theory 28(2), 2018, pp. 270-292.

[28] Whelan, C., "Managing dynamic security networks: Towards the strategic managing of cooperation, coordination and collaboration", Security Journal 30(1), 2017, pp. 310-327.

[29] Vangen, S., J.P. Hayes, and C. Cornforth, "Governing Cross-Sector, Inter-Organizational Collaborations", Public Management Review 17(9), 2015, pp. 1237-1260.

[30] Purdy, J.M., "A Framework for Assessing Power in Collaborative Governance Processes", Public Administration Review 72(3), 2012, pp. 409-417.

[31] Ingold, K., and M. Fischer, "Drivers of collaboration to mitigate climate change: An illustration of Swiss climate policy over 15 years", Global Environmental Change 24, 2014, pp. 88-98.

[32] Matthews, N., and B. Missingham, "Social Accountability and Community Forest Management: The Failure of Collaborative Governance in the Wombat Forest", Development in Practice 19(8), 2009, pp. 10521063.

[33] Chen, B., "Antecedents or Processes? Determinants of Perceived Effectiveness of Interorganizational Collaborations for Public Service Delivery", International Public Management Journal 13(4), 2010, pp. 381-407.

[34] Meijer, A.J., "Co-production in an Information Age: Individual and Community Engagement Supported by New Media", VOLUNTAS: International Journal of Voluntary and Nonprofit Organizations 23(4), 2012, pp. 1156-1172.

[35] Voorberg, W.H., V.J.J.M. Bekkers, and L.G. Tummers, "A Systematic Review of Co-Creation and CoProduction: Embarking on the social innovation journey", Public Management Review 17(9), 2015, pp. 1333-1357.

[36] Szopik-Depczyńska, K., K. Cheba, I. Bąk, and G. Ioppolo, "User-Driven Innovation in Poland: 
Determinants and Recommendations", Sustainability 12(1), 2020, pp. 171.

[37] Magno, F., and F. Cassia, "Public administrators' engagement in services co-creation: factors that foster and hinder organisational learning about citizens", Total Quality Management \& Business Excellence 26(11-12), 2015, pp. 1161-1172.

[38] Mariadoss, B.J., P.S. Tansuhaj, and N. Mouri, "Marketing capabilities and innovation-based strategies for environmental sustainability: An exploratory investigation of B2B firms", Industrial Marketing Management 40(8), 2011, pp. 1305-1318.

[39] Bussu, S., and M.T. Galanti, "Facilitating coproduction: the role of leadership in coproduction initiatives in the UK", Policy and Society O(0), 2018, pp. 1-21.

[40] Frieling, M.A., S.M. Lindenberg, and F.N. Stokman, "Collaborative Communities Through Coproduction: Two Case Studies", The American Review of Public Administration 44(1), 2014, pp. 35-58.

[41] Sicilia, M., A. Sancino, T. Nabatchi, and E. Guarini, "Facilitating co-production in public services: management implications from a systematic literature review", Public Money \& Management 39(4), 2019, pp. 233-240.

[42] Jagtap, S., "Co-design with marginalised people: designers' perceptions of barriers and enablers", CoDesign, 2021, pp. 1-24.

[43] Bovaird, T., and E. Loeffler, "From Engagement to Coproduction: The Contribution of Users and Communities to Outcomes and Public Value", VOLUNTAS: International Journal of Voluntary and Nonprofit Organizations 23(4), 2012, pp. 1119-1138.

[44] Carroll, J.M., and M.B. Rosson, "Participatory design in community informatics", Design Studies 28(3), 2007, pp. 243-261.

[45] Paarlberg, L.E., and S. Gen, "Exploring the Determinants of Nonprofit Coproduction of Public Service Delivery: The Case of k-12 Public Education", The American Review of Public Administration 39(4), 2009, pp. 391-408.

[46] Parrado, S., G.G.V. Ryzin, T. Bovaird, and E. Löffler, "Correlates of Co-production: Evidence From a FiveNation Survey of Citizens", International Public Management Journal 16(1), 2013, pp. 85-112.

[47] Jakobsen, M., "Can Government Initiatives Increase Citizen Coproduction? Results of a Randomized Field Experiment", Journal of Public Administration Research and Theory 23(1), 2013, pp. 27-54.

[48] Sørensen, E., and J. Torfing, "Co-initiation of Collaborative Innovation in Urban Spaces", Urban Affairs Review 54(2), 2018, pp. 388-418.

[49] Crosby, B.C., P. 't Hart, and J. Torfing, "Public value creation through collaborative innovation", Public Management Review 19(5), 2017, pp. 655-669.

[50] Tindall, R.M., M. Ferris, M. Townsend, G. Boschert, and S. Moylan, "A first-hand experience of co-design in mental health service design: Opportunities, challenges, and lessons", International Journal of Mental Health Nursing, 2021, pp. 1.

[51] Wilkinson, C.R., and A. De Angeli, “Applying user centred and participatory design approaches to commercial product development", Design Studies 35(6), 2014, pp. 614-631.

[52] Palumbo, R., and R. Manna, "What if things go wrong in co-producing health services? Exploring the implementation problems of health care co-production", Policy and Society O(0), 2017, pp. 1-18.

[53] Needham, D.C., and S. Carr, Co-production: an emerging evidence base for adult social care transformation, Social Care Institute for Excellence, 2009.

[54] Brandsen, T., and V. Pestoff, "Co-production, the third sector and the delivery of public services: An introduction", Public Management Review 8(4), 2006, pp. 493-501.

[55] Jakobsen, M., and S.C. Andersen, "Coproduction and Equity in Public Service Delivery", Public Administration Review 73(5), 2013, pp. 704-713.

[56] Kushniruk, A., and C. Nøhr, "Participatory Design, User Involvement and Health IT Evaluation", Evidence-Based Health Informatics, 2016, pp. 13.

[57] Loeffler, E., and T. Bovaird, "User and Community CoProduction of Public Services: What Does the Evidence Tell Us?", International Journal of Public Administration 39(13), 2016, pp. 1006-1019.

[58] Mazzei, M., S. Teasdale, and F. Cal, "Co-production and the third sector: conceptualising different approaches to service user involvement", Public Management Review, 2019 , pp. 33.

[59] Sicilia, M., E. Guarini, A. Sancino, M. Andreani, and R. Ruffini, "Public services management and co-production in multi-level governance settings", International Review of Administrative Sciences 82(1), 2016, pp. 8-27.

[60] Doke, K., Q. Yuan, M. Gasco-Hernandez, et al., "Supporting Resilience in Rural Emergency Preparedness and Response Through Improved Information Access", GetMobile: Mobile Computing and Communications 24(2), 2020, pp. 5-11.

[61] Scapens, R.W., "Researching management accounting practice: The role of case study methods", The British Accounting Review 22(3), 1990, pp. 259-281.

[62] Marshall, C., and G.B. Rossman, Designing Qualitative Research, SAGE Publications, 2014.

[63] Yin, R., Case study research: Design and methods (applied social research methods), Sage, London and Singapore: Sage, 2009.

[64] Saldaña, J., The Coding Manual for Qualitative Researchers, SAGE, 2015.

[65] Charmaz, K., Constructing Grounded Theory, SAGE, 2014.

[66] Crosby, B.C., and J.M. Bryson, "Integrative leadership and the creation and maintenance of cross-sector collaborations", The Leadership Quarterly 21(2), 2010, pp. 211-230.

[67] Dearden, A., and H. Rizvi, "Participatory IT Design and Participatory Development: A comparative review", 2008, pp. 11.

[68] Saz-Carranza, A., and F. Longo, "Managing Competing Institutional Logics in Public-Private Joint Ventures", Public Management Review 14(3), 2012, pp. 331-357. 
Page 2604 